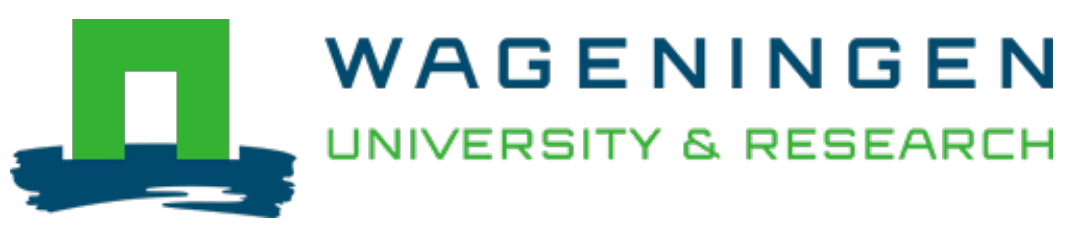

\title{
Larval source management for malaria control: prospects for new technologies and community involvement
}

Innovative strategies for vector control

Koenraadt, C.J.M.

https://doi.org/10.3920/978-90-8686-895-7_8

This article is made publicly available in the institutional repository of Wageningen University and Research, under the terms of article $25 \mathrm{fa}$ of the Dutch Copyright Act, also known as the Amendment Taverne. This has been done with explicit consent by the author.

Article 25 fa states that the author of a short scientific work funded either wholly or partially by Dutch public funds is entitled to make that work publicly available for no consideration following a reasonable period of time after the work was first published, provided that clear reference is made to the source of the first publication of the work.

This publication is distributed under The Association of Universities in the Netherlands (VSNU) 'Article $25 \mathrm{fa}$ implementation' project. In this project research outputs of researchers employed by Dutch Universities that comply with the legal requirements of Article $25 \mathrm{fa}$ of the Dutch Copyright Act are distributed online and free of cost or other barriers in institutional repositories. Research outputs are distributed six months after their first online publication in the original published version and with proper attribution to the source of the original publication.

You are permitted to download and use the publication for personal purposes. All rights remain with the author(s) and / or copyright owner(s) of this work. Any use of the publication or parts of it other than authorised under article $25 \mathrm{fa}$ of the Dutch Copyright act is prohibited. Wageningen University \& Research and the author(s) of this publication shall not be held responsible or liable for any damages resulting from your (re)use of this publication.

For questions regarding the public availability of this article please contact openscience.library@,wur.nl 


\title{
8. Larval source management for malaria control: prospects for new technologies and community involvement
}

Constantianus J.M. Koenraadt

Laboratory of Entomology, Wageningen University \& Research, P.O. Box 16, 6700 AA Wageningen, the

Netherlands; sander.koenraadt@wur.nl

\begin{abstract}
Tackling the aquatic stages of anopheline malaria vectors is a key element in integrated vector management (IVM) programmes. The first large trials with Bacillus thuringiensis var. israelensis (Bti) as a novel biological control agent demonstrated that its impact can be highly effective, but context dependent. To better understand this dependency, there is a need to answer fundamental questions on mosquito larval ecology. At the same time, new technologies enter the stage, e.g. drones for delivery of Bti and approaches with genetically modified (GM) mosquitoes, that can aid field control operations. Such developments are promising, but any larval source management (LSM) programme also needs the involvement of communities from the very start in order to implement sustainable programmes. In this chapter, progress in answering fundamental questions on larval ecology is reviewed and recent examples that specifically aimed to assess the feasibility of involving communities in IVM programs for malaria control are discussed.
\end{abstract}

Keywords: larval source management, vector control, community engagement, malaria

\section{Background and rationale}

Despite tremendous efforts to curb malaria morbidity and mortality, further progress in malaria control has slowed down recently, and new tools are needed to help reduce the impact of this debilitating disease. Both long-lasting insecticidal nets (LLINs) and indoor residual spraying (IRS) have been the mainstay in vector control efforts (Bhatt et al. 2015), but insecticide resistance and the slow market entry of new formulations have hampered further progress (Hemingway 2018). In addition to resistance, also the implementation of LLIN programmes presents major challenges. Over the years, it has become clear that community engagement strategies play an essential role in the roll-out and scale-up of interventions. Although there is large variation by country, the World Health Organization currently estimates LLIN coverage, i.e. the proportion of households owning at least one LLIN, at $72 \%$. However, this does not imply that all household members have access to a net, because only $40 \%$ of the households in sub-Saharan Africa have sufficient nets for all occupants (WHO 2019). In other words, possession of a net does not guarantee its actual use, and multiple studies have in fact reported on the improper use and even misuse of nets (Eisele et al. 2011, Minakawa et al. 2008, Okumu 2020). In such a case, it is essential that effective communication messages are delivered so that people understand why they should use a net and how to properly install it for protection at night.

Although insecticide-based approaches are the core of the current global malaria control efforts, alternative approaches are needed that tackle the resistance problem and that offer more sustainable solutions (Hemingway 2017, Koenraadt and Takken 2018, McGraw and O'Neill 2013). Several tools and technologies are available for this in our toolbox (Takken and Knols 2009, Williams et al. 2018). Whereas some of them, such as house screening, already have a longer history 
of proven efficacy (Kirby et al. 2009, Lindsay et al. 2002), others are relatively new and are still undergoing evaluation of their epidemiological impact, such as odour-based removal trapping of adult malaria vectors and genetic modification to replace malaria vector populations with strains that are refractory to the malaria parasite (Alphey et al. 2002, Homan et al. 2016, McGraw and O'Neill 2013). All the above described strategies target the adult stages of the malaria vector and do not take the source of malaria vectors into account. There is great potential to also include the management of larval sources in vector control programs. Besides the fact that there is a need to quantify the epidemiological impact of larval vector control (Williams et al. 2018), there is also a need to evaluate how communities can be involved in such programs, as many of the larval breeding sites can be found in the peri-domestic environment or are the result of agricultural activities, such as drainage and irrigation (Killeen et al. 2002, Mukabana et al. 2006).

Larval source management involves the manipulation, alteration or management of water sources that could harbour the immature, aquatic stages of malaria vectors. Central to this concept is the fact that control takes place at the earliest life stage possible and, in this way, it contributes to the reduction of adult vector populations. Moreover, in their adult stage, disease vectors display a variety of behaviours, such as indoor versus outdoor feeding and resting. Also, host feeding preferences vary widely, which leads to a wide diversity of niches that mosquito vectors occupy. As a result, conventional control tools may not always affect the adult mosquito, and control efforts aimed at the adult stages may thus be jeopardised. For example, indoor residual spraying affects those mosquitoes that feed and/or rest inside, whereas outdoor feeding mosquitoes are missed and will still be able to sustain malaria transmission (Sherrard-Smith et al. 2019).

As control of the larval breeding sites is indiscriminate of the feeding and resting behaviours of the adult forms later in life, it would thus ensure that vector populations are reduced in both the indoor and the outdoor environment, thereby contributing to more efficient malaria elimination efforts. Recently, some interesting insights in the genetic make-up and diversity of larval versus adult Anopheles gambiae s.s. have been obtained that support this notion. Riehle et al. (2011) noted that the genetic composition of larval An. gambiae s.s. populations, based on unbiased sampling of larval habitats, was different from the genetic composition of adult An. gambiae s.s. collected indoors. Clearly, a genetic sub-group existed that was represented in the larval stage, but that was absent in the indoor sampled adult mosquitoes. This suggested that this subgroup is exophilic and not captured with conventional indoor trapping techniques. Further isolation of this exophilic sub-group (named GOUNDRY) revealed that it is actually more susceptible to Plasmodium falciparum infection than its endophilic counterpart (the ENDO subgroup of An. gambiae s.s.). These genetic complexities are a good example of how vector population dynamics may complicate efforts to control malaria, but also demonstrate the added value that larval source management may have in terms of the selective pressures that it has in comparison with adult vector control (Crawford et al. 2016).

\section{Fundamental aspects of larval ecology of malaria vectors}

For successful implementation of larval control programmes, it is essential to have a thorough understanding of ecological factors that affect the development and survival of malaria mosquito larvae in their aquatic habitats. Of the $\mathbf{4 6 2}$ formally named species belonging to the Anopheles genus, approximately 70 are actually involved in the transmission of malaria (Hay et al. 2010, Massey et al. 2016). Larvae of these anopheline species can be found in a wide diversity of habitats, ranging from small, temporary pools and puddles to large, more permanent water bodies. Some of these sites can be fully exposed to the sun, e.g. sites in which Anopheles coluzzii breeds in Africa, 
whereas other malaria vector species prefer forested, and hence more shaded sites, e.g. Anopheles dirus in Asia. The aquatic life cycle of all these species starts when a gravid female mosquito deposits her eggs on or very near the water (Minakawa et al. 2001).

Various cues originating from the aquatic habitat play a role in the detection and subsequent selection of the site for oviposition. These include visual cues, e.g. site tone, as well as chemical cues, i.e. volatile infochemicals (Blackwell and Johnson 2000, McCrae 1984). Some of these chemical cues are likely to have a bacterial origin, and may hence indicate the suitability of the site in terms of bacterial food availability for the developing offspring (Sumba et al. 2004). One particular volatile compound derived from water infused with soil from a natural breeding site that shows strong attraction towards gravid female mosquitoes is cedrol (Lindh et al. 2015). Both in a laboratory and in a field setting, this compound elicited strong egg laying responses from gravid female An. gambiae s.s.. Other cues may emanate from conspecific larvae already present in the breeding habitat, and these can either have an attracting or a repelling effect. Recently, it has been established that two volatiles, nonane and 2,4-pentanedione, are released by early stage An. coluzzii larvae, and these volatiles may indicate the suitability of the site for development of the offspring of the ovipositing female (Schoelitsz et al. 2020). The same study reported that the presence of conspecific, late stage (fourth instar) larvae was associated with the release of two repellent volatile compounds, dimethyl disulfide and dimethyl trisulfide (Schoelitsz et al. 2020). These compounds may signal a predation risk to the gravid female, because it is known that older An. coluzzii larvae can cannibalise on their younger conspecifics or negatively affect their development rate. These effects seem to be mostly mediated by limitations in food and space for the larvae (Koenraadt and Takken 2003, Koenraadt et al. 2004).

Once eggs have been deposited, they may face conditions that are detrimental to their survival and development, such as prolonged drought which causes dehydration, or intense rains which results in the flushing of eggs. In comparison with other mosquito genera, in particular Aedes, the eggs of Anopheles have a limited capability to survive dry periods. For eggs of An. gambiae s.l. this has been estimated at 12-16 days (Beier et al. 1990, Holstein 1954). Interestingly, if eggs are not directly floating on the water surface, but are rather stuck on the wet mud surrounding an aquatic habitat as a result of prolonged drought, larvae do have the capability to emerge from these eggs and crawl a short distance of a few centimetres towards the actual water body and continue their development (Koenraadt et al. 2003, Miller et al. 2006). Interestingly, finding eggs on wet mud may actually not be 'accidental', as there is evidence that eggs are more likely to be found outside than inside water puddles (Miller et al. 2006). In addition to survival in the egg stage, the different larval stages can survive up to a maximum of three to five days if they end up on damp soil as a result of an aquatic habitat completely drying out (Koenraadt et al. 2003). The above described findings on drought resistance and survival have important implications for larval control strategies, as they all suggest that interventions should not only target water bodies themselves, but also recently dried out habitats to ensure a maximum reduction in adult mosquito numbers.

As discussed above, the dry season may have detrimental effects on the population dynamics of the larval stages of An. gambiae. Although this species also breeds in water bodies that are the result of human activity, such as water-filled brick pits, cattle drinking sites and borehole run-off, the onset of the rainy season results in numerous, temporary pools and puddles that support the development of large numbers of An. gambiae larvae (Coetzee et al. 2000). Interestingly, rains that are too intense could result in the flushing of larvae or in the ejection of larvae from their breeding site. As a consequence, nightly losses for the different developmental stages have been estimated at 5 and $18 \%$ for the younger (L1) and older (L4) larval stages, respectively (Paaijmans 
et al. 2007). Remaining larvae can experience high levels of competition, which in the most severe circumstances, can result in predation of conspecifics, or in delayed development and increased mortality (Koenraadt and Takken 2003). The outcome of competition can be different for the different species of the An. gambiae complex. In places where both sibling species are sympatric, Anopheles arabiensis is the more dominant species during the dry season as it is generally more drought resistant, while the relative abundance of An. gambiae increases during the wet season (Kirby and Lindsay 2003, Koenraadt et al. 2004). This can be explained by the differential sensitivity of the two species to high temperatures, with An. arabiensis adults being able to withstand higher temperatures and express higher survival at higher temperatures (Kirby and Lindsay 2003). In addition, differences can be explained by the asymmetric levels of competition between the two species in their aquatic habitats: An. gambiae s.s. generally is a better competitor, as evidenced by the fact that larvae of An. arabiensis had an extended development time in mixed sibling species populations. Also, mortalities of An. arabiensis were higher than those of An. gambiae s.s., although latter effects depended on habitat size (Paaijmans et al. 2009).

In conclusion, numerous fundamental aspects on the larval ecology of malaria vectors have been unravelled in the past decades. In particular the identification of key chemical compounds that stimulate oviposition behaviour (cedrol, nonane and 2,4 pentanedione) offers opportunities for exploitation in attract-and-kill strategies. This, however, requires careful testing of formulations that combine attractant and lethal compounds, as the lethal compounds should not exert a strong repellent effect. This would simply negate the positive effect of the attractant. For example, it has been shown that the larvicide temephos has a strong deterrent effect on gravid An. gambiae s.l. females, but not on gravid Culex quinquefasciatus. On the contrary, Bti did not cause any repellent effects on oviposition (Mwingira 2020), making it a more suitable candidate in attract-and-kill strategies that target the larval stages. As an alternative to temephos and Bti, a large list of plant-derived compounds has been evaluated for their larvicidal effects against various Anopheles species. These compounds either exert direct toxic effects, act as mimics of insect growth regulators, or are used as essential oils that interfere with oxygen uptake of the aquatic larvae (reviewed in Muema et al. 2017). Similarly, plant-derived compounds can also have a repellent rather than a toxic effect. These are flavours and fragrances of plant essential oils that are categorised as monoterpenes, sesquiterpenes and aliphatic chemicals. Such compounds could thus be incorporated in push-pull strategies, in which the repellent compound is used to deter gravid females away from specific locations and lure them to other locations where their offspring will not be able to complete development. Sufficient opportunities thus exist to develop effective attract-and-kill formulations. When used wisely, e.g. in rotational schemes, these strategies would also reduce the selective pressure on resistance development.

\section{New technologies in larval source management}

Long before the formal identification of Anopheles mosquitoes as vectors of Plasmodium parasites by Ronald Ross and others in the late $19^{\text {th }}$ century, people were already aware of the association between 'periodic fevers' and the proximity of swampy areas. Without the availability of tools to identify disease causing organisms, which took a major flight with the development of the microscope by van Leeuwenhoek in the late $17^{\text {th }}$ century and the germ theory of Louis Pasteur and Robert Koch, people ascribed their fevers and sickness to miasmas or noxious forms of bad air (Dobson 2007). Numerous descriptions of the devastating impacts of malarial fevers can be found in the historical texts of Egyptian, Greek, Roman and Chinese writers, and date back to several centuries B.C. As a consequence of the awareness of this association, the first forms of larval vector control were already undertaken through, for example, drainage of swamp areas and 
the implementation of sanitary measures, such as cleaning sewers and pumping bilge water out of ships (which constitutes a potential breeding spot for Aedes aegypti). Of course, we can only speculate about the actual impact of these control measures, as the scientific evidence of these historical programmes is simply lacking.

The first well-described trial of a malaria vector intervention was carried out in Italy by Angelo Celli among railway workers, and included the combination of house screening, whitewashing of internal walls, burning of specific powders (most likely including pyrethrum) and the use of protective clothing (Ferroni et al. 2012). Malaria was contracted in $92 \%$ of the people in the control arm, whereas only $4 \%$ contracted malaria in the intervention arm of the trial. Although these intervention techniques were seemingly simple and straightforward to carry out, the example also demonstrated the logistical and analytical challenges of combining interventions, and the need for intersectoral collaboration, as in this case railway workers were the targeted group. In addition, Celli recognised the importance of public education and the role of the living conditions of affected communities in tackling the disease. Interestingly, Celli noted that interventions were sometimes met with apathy, ignorance and prejudice, and trial participants commented that they were not wild animals and did not want to sleep in cages (Ferroni et al. 2012), highlighting the need for community involvement in vector control programmes. The work by Celli can thus be considered as an example of an integrated vector management strategy avant la lettre.

Many of the above described older techniques, such as drainage, house screening and personal protection (e.g. bed nets), are still part of malaria vector control efforts today. At the same time, many new vector control technologies have been developed and added to our toolbox (Takken and Knols 2009), including the development of lure-and-kill strategies based on host-derived odours (e.g. traps and eave tubes (Homan et al. 2016, Knols et al. 2016)), the development of biological control (e.g. natural enemies and organisms pathogenic to the larval and adult stages (Bukhari et al. 2013)), and the advancement of genetic based approaches (e.g. release of insects carrying a dominant lethal, or RIDL (Phuc et al. 2007)). Here I will highlight new developments in a selected number of tools that specifically target the larval stages of malaria vectors, and further elaborate on how they can be taken up in LSM programs.

The potential of Bacillus thuringiensis var. israelensis (Bti) and other Bacillus preparations (e.g. Bacillus sphaericus) for the biological control of African anophelines has been recognised since the early 1980's (Pant et al. 1981). This took a major flight with the evaluation of its impact within largescale epidemiological field trials in different ecological settings (reviewed in Derua et al. 2019). These trials demonstrated significant reductions in the prevalence or incidence of malaria in, for example, the urban environment of Dar es Salaam, Tanzania (Geissbühler et al. 2009), and the highlands of western Kenya (Fillinger et al. 2009). In the floodplains of the Gambia, however, the impact of the application of Bti to larval breeding sites on malaria was not observed, most likely through the abundance of large riverine areas with extensive flooding, which resulted in highly mobile and also inaccessible sites (Majambere et al. 2010). One option to tackle this challenge is the use of drones to deliver the biolarvicides to water bodies. Various trials are currently underway to evaluate the feasibility and cost-effectiveness of this approach. Regardless of their usefulness in the actual application of Bti, drones may also greatly aid in the mapping and identification of potential breeding sites, and could thus contribute to more efficient LSM (Carrasco-Escobar et al. 2019, Hardy et al. 2017).

Methods that cause the asphyxiation of larvae have been in use since the very first vector control attempts and were mostly based on the application of mineral and paraffin oils to the water 
surface. Similarly, various monomolecular surface films have been developed and tested in different ecological settings with variable effects (reviewed in Nayar and Ali 2003). A downside of these surface films is that when they are applied in the open field, they may break up as a result of wind and vegetation present in the water, and hence lose their effectiveness. However, newer formulations, such as Aquatain, have a higher resistance against these disturbances (Bukhari and Knols 2009, Mbare et al. 2014). A field trial in rice fields in Kenya demonstrated a strong reduction in the aquatic stages of anopheline and culicine larvae. Moreover, the product reduced water loss due to evaporation. Importantly, no negative effects on non-target organisms were observed and also the development of rice plants and the rice yield were not affected (Bukhari et al. 2011). Despite their proven efficacy in entomological field trials, these types of products have not yet been incorporated to their fullest extent in LSM programs. Randomised controlled trials, following the guidelines of the Vector Control Advisory Group (VCAG) of WHO, are needed in order to demonstrate the impact of monomolecular surface films on malaria incidence or prevalence, and thus to demonstrate the public health value of such a new intervention.

A relatively new player in the field is the use of RNA interference as a mechanism to silence genes that are essential in the development of Anopheles larvae, and that induce mortality as a result. The idea is to expose larvae to RNAi nano-particles that are incorporated in larval food, which is ingested during development (Zhang et al. 2010, 2015). The technique has been further developed by genetically engineering of Saccharomyces cerevisiae (baker's yeast) to express short hairpin RNA that silences neural development genes. The yeast thus acts as the food source as well as an RNAi delivery platform, and could thus be considered an RNA pesticide. Proof of concept of this tool has been provided for a number of disease vectors, including Ae. aegypti, Aedes albopictus, Culex quinquefasciatus and An. gambiae (Mysore et al. 2017, 2019). The concept opens up a plethora of opportunities to specifically target genes that are essential in the development of the pest species, and it may thus be less vulnerable to insecticide resistance than other strategies. Nevertheless, the approach will require a substantial amount of regulatory approval, as it will be considered a genetic modified organism (GMO) that will be released in the open field (Lopez et al. 2019). As such, it is likely that the tool will not be available for LSM programmes any time soon.

\section{Role of communities in malaria vector control}

In the scientific literature, one may come across many different terms that are used to describe the roles and levels of involvement of communities in (vector-borne) disease control. These include, among others, 'community participation', 'community engagement', 'community mobilisation', 'community sensitisation' and 'community empowerment'. The types of activities and tools that describe the role of communities are highly diverse and are culture and context dependent. They range from school-based education programmes and focus group discussions to the provision of incentives and health care insurance. All of these have the aim to provide communities with a more active role in an intervention programme (e.g. in decision making), rather than undergoing a certain intervention without any input. The ultimate aim of these activities is to increase the uptake and coverage of an intervention so that maximum impact on disease reduction is achieved.

A search on PubMed to quantify the attention in the scientific literature for community participation and vector control (using 'vector AND control AND community AND participation' as keywords, search date: July 2020) revealed 429 publications. Of these, the majority focused on malaria (33\%) and dengue (31\%). Other vector-borne diseases received far less attention in the scientific literature, with leishmaniasis (1.4\%) and onchocerciasis (1.6\%) as the two vectorborne diseases with the least publications on community participation. Of the 140 malaria-related 
studies on community participation, 19 were qualified as a 'review'. Interestingly, eight were labelled as 'randomised controlled trial'. In most cases, community participation or engagement strategies were in that case included in the study of vector control interventions, such as IRS (e.g. Keating et al. 2011), insect growth regulators (e.g. Yapabandara et al. 2001), larvivorous fish (e.g. Fletcher et al. 1992) or the combination of larval source management and house improvement (McCann et al. 2017). None of the identified studies included a comparison in which the effect of community participation by itself was evaluated at an epidemiological level. In other words, the studies did not include intervention arms evaluating a vector control tool with and without community participation. This probably uncovers the weakness of community participation in integrated vector control efforts: there is no good handle on the quantitative impact of community participation on epidemiological outcomes of malaria. One could argue that that may be an unrealistic appeal, especially because of the logistical complexities of such a study, but without any assessment, we remain in the dark about the true value of engaging communities in vector control. As mentioned, many different approaches exist to involve communities as stakeholders in a vector control program, but in recent years, also in this field innovative approaches have been tested and evaluated. A few of these will be highlighted here.

Because farming activities, such as rice irrigation and drainage construction, are strongly associated with malaria risk, involving farmers in vector control efforts has received much attention in the literature. The so-called Farmer Field School is an approach that has been successfully implemented in crop protection programs, and it has been argued that a similar approach can also be used for malaria vector control (Van den Berg and Knols 2006). The Farmer Field School provides a form of education that uses experiential learning methods with the aim to increase farmers' expertise. The concept is that groups of farmers meet at regular (e.g. weekly) intervals, take observations and sample populations and characteristics of harmful and beneficial organisms, plants, soil and environmental conditions. Such data are analysed and discussed and can lead to decision-making on experimental action to be evaluated the following week. In the case of malaria vector control, this could for example result in improved drainage channels with less standing water which, on its turn, results in reduced vector populations and hence reduced transmission of disease. In addition, besides these direct effects, also more indirect effects can follow. For example, increased profit because of better water management can result in better housing and nutrition, resulting in less disease. Also increased awareness and less use of (agro)insecticides and hence reduced selective pressure for insecticide resistance can positively affect malaria control efforts in this way (Van den Berg and Knols 2006). Ideally, the curricular activities on mosquito ecology are incorporated into ongoing Farmer Field School programs on crop management, so that an integrated pest and vector management (IPVM) approach can be rolled out. Ecologists at African institutions can play an important role in this, and thus need the full support at academic level to train the next generation of trainers and practitioners (Mukabana et al. 2006).

Whereas Farmer Field Schools are specifically aimed at a particular profession, other approaches, such as the Open Space technique, aim to elicit the attention of communities at large. By formulating provocative 'calling questions' prior to public meetings, those interested in a specific topic, e.g. malaria control, come together at a specific Open Space meeting venue. Rather than having a pre-set agenda in this approach, topics for discussion will be collected and determined during a first round of brainstorming. This is followed by group discussions during which participants can move freely from one topic to the other so as to promote 'cross-pollination'. The Open Space technique is a bottom-up approach that is frequently implemented in company settings, for example when companies need to re-organise and to go through a change process collectively. This approach was also tested in a public health/malaria context in Rwanda (Ingabire 
et al. 2014). Two Open Space meetings engaged the local community in the malaria problem and resulted in community-formulated, sustainable suggestions for malaria control. One consisted of the formation of 'community malaria action teams' (CMATs), which aimed to deliver malaria prevention messages at village level. The other suggestion was the implementation of a mosquito LSM program in the rice fields using biological substances, in this case Bti (Ingabire et al. 2016). Evaluation of the 6-month LSM trial revealed that community awareness and support for LSM increased. A high effectiveness of Bti in terms of mosquito abundance and nuisance biting was perceived by the community (Ingabire et al. 2017), and later also confirmed in independent entomological surveys (Hakizimana 2019). Especially this community perception is critical for the success of a control programme, because without it, interest and motivation can rapidly wane, resulting in only short-term benefits of the intervention.

Vector surveillance constitutes an essential part of malaria control programmes and is often performed by well-trained staff at local, regional or national level. It needs to be performed repeatedly, so as to obtain an idea of the temporal dynamics in vector populations. It also requires high spatial coverage so as to identify areas that are most at risk of malaria transmission, which could then be specifically targeted with (vector) control tools. The need for informative data that have a high temporal and spatial resolution represents challenges, because often the number of staff and available budget is limited. The consequence is that specific transmission areas may be overlooked or that peaks in transmission may not be detected in a timely fashion. The question is whether such gaps in surveillance could be solved by involving the general public in the reporting of mosquito bionomic data (Bartumeus et al. 2018). If set-up rightly, such a'citizen science' approach may generate a large amount of relevant entomological data, while at the same time engaging and educating communities about malaria (vector) biology. This approach has been successfully implemented in several developed countries for the surveillance of native and invasive mosquito species (reviewed in Kampen et al. 2015) and is considered an important tool for the detection of (invasive) vectors and their associated diseases by the European Centre for Disease Prevention and Control (ECDC 2014). The question remains whether the same approach can also be used to enable 'passive' monitoring of Anopheles mosquitoes involved in the transmission of malaria in rural African settings.

In a recent study from Tanzania, groups of volunteer participants were asked every month to rank areas around their villages from low to high outdoor-biting mosquito density based on their own knowledge and experience (Mwangungulu et al. 2016). This ranking was then validated with actual mosquito abundance reported from odour-baited traps. Results showed that such community knowledge and experience was a reliable means for identifying areas with true low or high mosquito densities, and this simple low-cost tool could thus guide large-scale implementation of mosquito control operations (Mwangungulu et al. 2016). Similarly, a 1-year citizen science project was set-up in five villages in southern Rwanda with the aim to contribute to malaria mosquito surveillance (Asingizwe et al. 2018, Murindahabi et al. 2018). In that study, a bottom-up approach was chosen by involving communities in the design of the citizen science program. This involved both the technical aspects (e.g. which trapping tool to use), as well as the social aspects of the program (e.g. how to organise data collection and reporting (Asingizwe et al. 2019)). On a monthly basis, data were collected on mosquito nuisance, numbers of mosquitoes in a hand-made trap and confirmed malaria cases in the household. Results showed significant correlations among reported nuisance, actual mosquito numbers and malaria cases, although these were strongly dependent on time (i.e. seasonal) and space (i.e. village vs sector level) (Murindahabi 2020). Collectively, the results from Tanzania and Rwanda suggest that by involving citizens in the reporting of observations, one could quickly 'scan' a larger area for potential hotspots of disease, 
and initiate further in-depth entomological surveillance. In other words, citizens could be the ears and eyes via which the malaria situation is monitored and eventually controlled.

Of course, in such a research project setting, it is relatively easy to keep villagers motivated to participate. Experimental projects generally do not last that long, and the challenge is to design programmes that are sustainable in the long run, particularly in terms of acceptability and participation, and that have high quality data and visible impact on the problem under study (Mboera et al. 2014, Rubin et al. 2020). After the study in Rwanda, volunteers showed significantly more involvement in malaria-related activities and had higher acceptance rates of IRS, which both could be considered as indicators of success of the project (Asingizwe et al. 2020). With regards to participation rates, these depend on numerous factors such as perceived severity of the malaria problem, perceived barriers and subjective norms. They are also determined by the (perceived) ease of use of reporting systems. The studies in Tanzania and Rwanda both used paper-based reporting systems. This approach could be more streamlined if data were to be collected via e.g. smartphone applications. Such digital approaches have already shown a lot of promise in the monitoring of invasive species in Europe, and even demonstrated that the citizen science approach picked up new invaded territories of the Asian tiger mosquito (Aedes albopictus) earlier than the traditional approach using oviposition traps (Palmer et al. 2017).

\section{Conclusions}

Innovations in larval vector control are a cornerstone in the global fight against malaria, and these include, among others, novel formulations of biological larvicides, RNA pesticides, monomolecular surface films, and attract-and-kill approaches based on volatile infochemicals. These innovations are often inspired by new knowledge in the (chemical) ecology, physiology and genomics of mosquito larvae. Therefore, it remains of utmost importance to keep investing in basic research as part of the Global Vector Control Response (WHO 2017). Implementation of these novel tools requires the involvement of communities from the very start of a control programme. Several new approaches have been evaluated recently (e.g. the Farmer Field School, Open Space, and citizen science) that specifically address ways of involving communities and keeping them motivated to contribute to the programme. Also, a toolbox of community-engagement approaches thus exists that can be used to effectively integrate new solutions into ongoing malaria control programs. Selection of approaches that have optimal local impact on malaria will be context and culture dependent, and this will require extensive collaborations across multiple sectors.

\section{References}

Alphey L, Beard CB, Billingsley P, Coetzee M, Crisanti A, Curtis C, Eggleston P, Godfray C, Hemingway J, Jacobs-Lorena M, James AA, Kafatos FC, Mukwaya LG, Paton M, Powell JR, Schneider W, Scott TW, Sina B, Sinden R, Sinkins S, Spielman A, Touré $Y$ and Collins FH (2002) Malaria control with genetically manipulated insect vectors. Science 298: 119-121.

Asingizwe D, Murindahabi MM, Koenraadt CJM, Poortvliet PM, van Vliet AJH, Ingabire CM, Hakizimana E, Mutesa L, Takken W and Leeuwis C (2019) Co-designing a citizen science program for malaria control in Rwanda. Sustain 11: 7012.

Asingizwe D, Poortvliet PM, Koenraadt CJM, Van Vliet AJH, Murindahabi MM, Ingabire C, Mutesa L and Feindt PH (2018) Applying citizen science for malaria prevention in Rwanda: an integrated conceptual framework. NJAS 86-87: 111122.

Asingizwe D, Poortvliet PM, van Vliet AJH, Koenraadt CJM, Ingabire CM, Mutesa L and Leeuwis C (2020) What do people benefit from a citizen science programme? Evidence from a Rwandan citizen science programme on malaria control. Malar J 19: 283. 
Bartumeus F, Oltra A and Palmer JRB (2018) Citizen science: a gateway for innovation in disease-carrying mosquito management? Trends Parasitol 34: 727-729.

Beier JC, Copeland R, Oyaro C, Masinya A, Odago WO, Oduor S, Koech DK and Roberts CR (1990) Anopheles gambiae complex egg-stage survival in dry soil from larval development sites in western Kenya. J Am Mosq Assoc 6: 105-109.

Bhatt S, Weiss DJ, Cameron E, Bisanzio D, Mappin B, Dalrymple U, Battle KE, Moyes CL, Henry A, Penny MA, Smith TA, Bennett A, Yukich J, Eisele TP, Eckhoff PA, Wenger EA, Briet O, Griffin JT, Fergus CA, Lynch M, Lindgren F, Cohen JM, Murray CLJ, Smith DL, Hay SI, Cibulskis RE and Gething PW (2015) The effect of malaria control on Plasmodium falciparum in Africa between 2000 and 2015. Nature 526: 207-211.

Blackwell A and Johnson SN (2000) Electrophysiological investigation of larval water and potential oviposition chemoattractants for Anopheles gambiae s.s. Ann Trop Med Parasitol 94: 389-398.

Bukhari T and Knols BGJ (2009) Efficacy of Aquatain (TM), a monomolecular surface film, against the malaria vectors Anopheles stephensi and An. gambiae s.s. in the laboratory. Am J Trop Med Hyg 80: 758-763.

Bukhari T, Takken W, Githeko AK and Koenraadt CJM (2011) Efficacy of aquatain, a monomolecular film, for the control of malaria vectors in rice paddies. PLoS One 6: e0021713.

Bukhari T, Takken W and Koenraadt CJM (2013) Biological tools for control of larval stages of malaria vectors - a review. Biocontrol Sci Technol 23: 987-1023.

Carrasco-Escobar G, Manrique E, Ruiz-Cabrejos J, Saavedra M, Alava F, Bickersmith S, Prussing C, Vinetz JM, Conn JE, Moreno M and Gamboa D (2019) High-accuracy detection of malaria vector larval habitats using drone-based multispectral imagery. PLoS Negl Trop Dis 13: e0007105.

Coetzee M, Craig M and le Sueur D (2000) Distribution of African malaria mosquitoes belonging to the Anopheles gambiae complex. Parasitol Today 16: 74-77.

Crawford JE, Riehle MM, Markianos K, Bischoff E, Guelbeogo WM, Gneme A, Sagnon N, Vernick KD, Nielsen R and Lazzaro BP (2016) Evolution of GOUNDRY, a cryptic subgroup of Anopheles gambiae s.l., and its impact on susceptibility to Plasmodium infection. Mol Ecol 25: 1494-1510.

Derua YA, Kweka EJ, Kisinza WN, Githeko AK and Mosha FW (2019) Bacterial larvicides used for malaria vector control in sub-Saharan Africa: Review of their effectiveness and operational feasibility. Parasit Vectors 12: 426.

Dobson M (2007) Disease: the extraordinary stories behind history's deadliest killers. Quercus, London, UK.

ECDC (2014) Guidelines for the surveillance of native mosquitoes in Europe. ECDC, Stockholm, Sweden.

Eisele TP, Thwing J, Keating J (2011) Claims about the misuse of insecticide-treated mosquito nets: are these evidencebased? PLoS Med 8: e1001019.

Ferroni E, Jefferson T and Gachelin G (2012) Angelo Celli and research on the prevention of malaria in Italy a century ago. J R Soc Med 105: 35-40.

Fillinger U, Ndenga B, Githeko A and Lindsay SW (2009) Integrated malaria vector control with microbial larvicides and insecticide-treated nets in western Kenya: a controlled trial. Bull World Health Org 87: 655-665.

Fletcher M, Teklehaimanot A and Yemane G (1992) Control of mosquito larvae in the port city of Assab by an indigenous larvivorous fish, Aphanius dispar. Acta Trop 52: 155-166.

Geissbühler Y, Kannady K, Chaki PP, Emidi B, Govella NJ, Mayagaya V, Kiama M, Mtasiwa D, Mshinda H, Lindsay SW, Tanner M, Fillinger U, de Castro MC and Killeen GF (2009) Microbial larvicide application by a large-scale, community-based program reduces malaria infection prevalence in urban Dar Es Salaam, Tanzania. PLoS One 4: e5107.

Hakizimana E (2019) Integrated vector management (IVM) as a tool for community empowerment towards malaria elimination in Rwanda. Wageningen University, Wageningen, the Netherlands.

Hardy A, Makame M, Cross D, Majambere S and Msellem M (2017) Using low-cost drones to map malaria vector habitats. Parasit Vectors 10: 29.

Hay SI, Sinka ME, Okara RM, Kabaria CW, Mbithi PM, Tago CC, Benz D, Gething PW, Howes RE, Patil AP, Temperley WH, Bangs MJ, Chareonviriyaphap T, Elyazar IR, Harbach RE, Hemingway J, Manguin S, Mbogo CM, Rubio-Palis $\mathrm{Y}$ and Godfray HC (2010) Developing global maps of the dominant Anopheles vectors of human malaria. PLoS Med 7: e1000209.

Hemingway J (2017) The way forward for vector control. Science 358: 998-999.

Hemingway J (2018) Resistance: a problem without an easy solution. Pest Biochem Physiol 151: 73-75. 
Holstein MH (1954) Biology of Anopheles gambiae - Research in French West Africa. World Health Organization monograph series no. 9. World Health Organization, Geneva, Switzerland.

Homan T, Hiscox A, Mweresa CK, Masiga D, Mukabana WR, Oria P, Maire N, Pasquale A Di, Silkey M, Alaii J, Bousema T, Leeuwis C, Smith TA and Takken W (2016) The effect of mass mosquito trapping on malaria transmission and disease burden (SolarMal): a stepped-wedge cluster-randomised trial. Lancet 388: 1193-1201.

Ingabire CM, Alaii J, Hakizimana E, Kateera F, Muhimuzi D, Nieuwold I, Bezooijen K, Rulisa S, Kaligirwa N, Muvunyi C, Koenraadt CJM, Mutesa L, Van Vugt M and Van Den Borne B (2014) Community mobilization for malaria elimination: application of an open space methodology in Ruhuha sector, Rwanda. Malar J 13: 167.

Ingabire CM, Hakizimana E, Kateera F, Rulisa A, Van Den Borne B, Nieuwold I, Muvunyi C, Koenraadt CJM, Van Vugt M, Mutesa $L$ and Alaii J (2016) Using an intervention mapping approach for planning, implementing and assessing a community-led project towards malaria elimination in the Eastern Province of Rwanda. Malar J 15: 594.

Ingabire CM, Hakizimana E, Rulisa A, Kateera F, Van Den Borne B, Muvunyi CM, Mutesa L, Van Vugt M, Koenraadt CJM, Takken W and Alaii J (2017) Community-based biological control of malaria mosquitoes using Bacillus thuringiensis var. israelensis (Bti) in Rwanda: Community awareness, acceptance and participation. Malar J 16: 399.

Kampen H, Medlock JM, Vaux AGC, Koenraadt CJM, Van Vliet AJH, Bartumeus F, Oltra A, Sousa CA, Chouin S and Werner D (2015) Approaches to passive mosquito surveillance in the EU. Parasit Vectors 8: 9.

Keating J, Locatelli A, Gebremichael A, Ghebremeskel T, Mufunda J, Mihreteab S, Berhane D and Carneiro P (2011) Evaluating indoor residual spray for reducing malaria infection prevalence in Eritrea: Results from a community randomized control trial. Acta Trop 119: 107-113.

Killeen GF, Fillinger U and Knols BG (2002) Advantages of larval control for African malaria vectors: low mobility and behavioural responsiveness of immature mosquito stages allow high effective coverage. Malar J 1: 8.

Kirby MJ, Ameh D, Bottomley C, Green C, Jawara M, Milligan PJ, Snell PC, Conway DJ and Lindsay SW (2009) Effect of two different house screening interventions on exposure to malaria vectors and on anaemia in children in The Gambia: a randomised controlled trial. Lancet 374: 998-1009.

Kirby MJ and Lindsay SW (2003) Effect of temperature on the development of the aquatic stages of Anopheles gambiae sensu stricto (Diptera: Culicidae). Bull Entomol Res 93: 375-381.

Knols BGJ, Farenhorst M, Andriessen R, Snetselaar J, Suer RA, Osinga AJ, Knols JMH, Deschietere J, Ng'habi KR, Lyimo IN, Kessy ST, Mayagaya VS, Sperling S, Cordel M, Sternberg ED, Hartmann P, Mnyone LL, Rose A and Thomas MB (2016) Eave tubes for malaria control in Africa: an introduction. Malar J 15: 404.

Koenraadt CJ, Majambere S, Hemerik L and Takken W (2004) The effects of food and space on the occurrence of cannibalism and predation among larvae of Anopheles gambiae s.l. Entomol Exp Appl 112: 125-134.

Koenraadt CJ, Paaijmans KP, Githeko AK, Knols BG and Takken W (2003) Egg hatching, larval movement and larval survival of the malaria vector Anopheles gambiae in desiccating habitats. Malar J 2: 20.

Koenraadt CJM, Githeko AK and Takken W (2004) The effects of rainfall and evapotranspiration on the temporal dynamics of Anopheles gambiae s.s. and Anopheles arabiensis in a Kenyan village. Acta Trop 90: 141-153.

Koenraadt CJM and Takken W (2003) Cannibalism and predation among larvae of the Anopheles gambiae complex. Med Vet Entomol 17: 61-66.

Koenraadt CJM and Takken W (2018) Integrated approach to malaria control. Science 359: 528-529.

Lindh JM, Okal MN, Herrera-Varela M, Borg-Karlson A-K, Torto B, Lindsay SW and Fillinger U (2015) Discovery of an oviposition attractant for gravid malaria vectors of the Anopheles gambiae species complex. Malar J 14: 119.

Lindsay SW, Emerson PM and Charlwood JD (2002) Reducing malaria by mosquito-proofing houses. Trends Parasitol 18: 510-514.

Lindsay SW, Parson L and Thomas CJ (1998) Mapping the ranges and relative abundance of the two principal African malaria vectors, Anopheles gambiae sensu stricto and An. arabiensis, using climate data. Proc R Soc London 265: 847-854.

Lopez SBG, Guimarães-Ribeiro V, Rodriguez JVG, Dorand FAPS, Salles TS, Sá-Guimarães TE, Alvarenga ESL, Melo ACA, Almeida RV and Moreira MF (2019) RNAi-based bioinsecticide for Aedes mosquito control. Sci Rep 9: 4038. 
Majambere S, Pinder M, Fillinger U, Ameh D, Conway DJ, Green C, Jeffries D, Jawara M, Milligan PJ, Hutchinson R and Lindsay SW (2010) Is mosquito larval source management appropriate for reducing malaria in areas of extensive flooding in The Gambia? A cross-over intervention trial. Am J Trop Med Hyg 82: 176-184.

Massey NC, Garrod G, Wiebe A, Henry AJ, Huang Z, Moyes CL and Sinka ME (2016) A global bionomic database for the dominant vectors of human malaria. Sci Data 3: 160014.

Mbare O, Lindsay SW and Fillinger U (2014) Aquatain ${ }^{\circledR}$ Mosquito Formulation (AMF) for the control of immature Anopheles gambiae sensu stricto and Anopheles arabiensis: dose-responses, persistence and sub-lethal effects. Parasit Vectors 7: 438.

Mboera LEG, Kramer RA, Miranda ML, Kilima SP, Shayo EH and Lesser A (2014) Community knowledge and acceptance of larviciding for malaria control in a rural district of east-central Tanzania. Int J Environ Res Publ Health 11:5137-5154.

McCann RS, van den Berg H, Diggle PJ, van Vugt M, Terlouw DJ, Phiri KS, Di Pasquale A, Maire N, Gowelo S, Mburu MM, Kabaghe AN, Mzilahowa T, Chipeta MG and Takken W (2017) Assessment of the effect of larval source management and house improvement on malaria transmission when added to standard malaria control strategies in southern Malawi: Study protocol for a cluster-randomised controlled trial. BMC Infect Dis 17: 639.

McCrae AW (1984) Oviposition by African malaria vector mosquitoes. II. Effects of site tone, water type and conspecific immatures on target selection by freshwater Anopheles gambiae Giles, sensu lato. Ann Trop Med Parasitol 78: 307318.

McGraw E and O'Neill SL (2013) Beyond insecticides: new thinking on an ancient problem. Nat Rev Microbiol 11:181-93.

Miller JR, Huang J, Vulule JM and Walker ED (2006) Life on the edge: African malaria mosquito (Anopheles gambiae s.l.) larvae are amphibious. Naturwissenschaften 94: 195-199.

Minakawa N, Dida GO, Sonye GO, Futami K and Kaneko S (2008) Unforeseen misuses of bed nets in fishing villages along Lake Victoria. Malar J 7: 165.

Minakawa N, Githure Jl, Beier JC and Yan G (2001) Anopheline mosquito survival strategies during the dry period in western Kenya. J Med Entomol 38: 388-392.

Muema JM, Bargul JL, Njeru SN, Onyango JO and Imbahale SS (2017) Prospects for malaria control through manipulation of mosquito larval habitats and olfactory-mediated behavioural responses using plant-derived compounds. Parasit Vectors 10: 184.

Mukabana WR, Kannady K, Kiama GM, Ijumba JN, Mathenge EM, Kiche I, Nkwengulila G, Mboera L, Mtasiwa D, Yamagata Y, van Schayk I, Knols BGJ, Lindsay SW, de Castro MC, Mshinda H, Tanner M, Fillinger U and Killeen GF (2006) Ecologists can enable communities to implement malaria vector control in Africa. Malar J 5: 9.

Murindahabi MM (2020) Citizen science for malaria vector surveillance in Rwanda. Wageningen University, Wageningen, the Netherlands.

Murindahabi MM, Asingizwe D, Poortvliet PM, van Vliet AJH, Hakizimana E, Mutesa L, Takken W and Koenraadt CJM (2018) A citizen science approach for malaria mosquito surveillance and control in Rwanda. NJAS 86-87: 101-110.

Mwangungulu SP, Sumaye RD, Limwagu AJ, Siria DJ, Kaindoa EW and Okumu FO (2016) Crowdsourcing vector surveillance: using community knowledge and experiences to predict densities and distribution of outdoor-biting mosquitoes in rural Tanzania. PLoS One 11: e0156388.

Mwingira V (2020) Olfactory mediation of oviposition in Anopheles mosquitoes: a new strategy for malaria vector control. Wageningen University, Wageningen, the Netherlands.

Mysore K, Hapairai LK, Sun L, Harper El, Chen Y, Eggleson KK, Realey JS, Scheel ND, Severson DW, Wei N and DumanScheel M (2017) Yeast interfering RNA larvicides targeting neural genes induce high rates of Anopheles larval mortality. Malar J 16: 461.

Mysore K, Li P, Wang CW, Hapairai LK, Scheel ND, Realey JS, Sun L, Severson DW, Wei N and Duman-Scheel M (2019) Characterization of a broad-based mosquito yeast interfering RNA larvicide with a conserved target site in mosquito semaphorin-1a genes. Parasit Vectors 12: 256.

Nayar JK and Ali A (2003) A review of monomolecular surface films as larvicides and pupicides of mosquitoes. JVector Ecol 28: 190-199.

Okumu F (2020) The fabric of life: What if mosquito nets were durable and widely available but insecticide-free? Malar J 19: 260. 
Paaijmans KP, Huijben S, Githeko AK and Takken W (2009) Competitive interactions between larvae of the malaria mosquitoes Anopheles arabiensis and Anopheles gambiae under semi-field conditions in western Kenya. Acta Trop 109: 124-130.

Paaijmans KP, Wandago MO, Githeko AK and Takken W (2007) Unexpected high losses of Anopheles gambiae larvae due to rainfall. PLoS One 2: e1146.

Palmer JRB, Oltra A, Collantes F, Delgado JA, Lucientes J, Delacour S, Bengoa M, Eritja R and Bartumeus F (2017) Citizen science provides a reliable and scalable tool to track disease-carrying mosquitoes. Nat Commun 8: 916.

Pant CP, Rishikesh N, Bang YH and Smith A (1981) Progress in malaria vector control. Bull World Health Organ 59: 325333.

Phuc HK, Andreasen MH, Burton RS, Vass C, Epton MJ, Pape G, Fu GL, Condon KC, Scaife S, Donnelly CA, Coleman PG, White-Cooper $\mathrm{H}$ and Alphey L (2007) Late-acting dominant lethal genetic systems and mosquito control. BMC Biol 5: 11.

Riehle MM, Guelbeogo WM, Gneme A, Eiglmeier K, Holm I, Bischoff E, Garnier T, Snyder GM, Li XZ, Markianos K, Sagnon $\mathrm{N}$ and Vernick KD (2011) A cryptic subgroup of Anopheles gambiae is highly susceptible to human malaria parasites. Science 331: 596-598.

Rubin NB, Kramer R, Mboera LEG, Lesser A and Miranda ML (2020) Process evaluation of a community-based microbial larviciding intervention for malaria control in rural Tanzania. Int J Environ Res Publ Health 17: 7309.

Schoelitsz B, Mwingira V, Mboera LEG, Beijleveld H, Koenraadt CJM, Spitzen J, van Loon JJA and Takken W (2020) Chemical mediation of oviposition by Anopheles mosquitoes: a push-pull system driven by volatiles associated with larval stages. J Chem Ecol 46: 397-409.

Sherrard-Smith E, Skarp JE, Beale AD, Fornadel C, Norris LC, Moore SJ, Mihreteab S, Charlwood JD, Bhatt S, Winskill P, Griffin JT and Churcher TS (2019) Mosquito feeding behavior and how it influences residual malaria transmission across Africa. PNAS 116: 15086-15096.

Sumba LA, Guda TO, Deng AL, Hassanali A, Beier JC and Knols BGJ (2004) Mediation of oviposition site selection in the African malaria mosquito Anopheles gambiae (Diptera: Culicidae) by semiochemicals of microbial origin. Int J Trop Insect Sci 24: 260-265.

Takken W and Knols BGJ (2009) Malaria vector control: current and future strategies. Trends Parasitol 25: 101-104.

Van den Berg H and Knols BGJ (2006) The Farmer Field School: a method for enhancing the role of rural communities in malaria control? Malar J 5: 3 .

WHO (2017) Global Vector Control Response 2017-2030. World Health Organization, Geneva, Switzerland.

WHO (2019) World Malaria Report 2019. World Health Organization, Geneva, Switzerland.

Williams YA, Tusting LS, Hocini S, Graves PM, Killeen GF, Kleinschmidt I, Okumu FO, Feachem RGA, Tatarsky A and Gosling RD (2018) Expanding the vector control toolbox for malaria elimination: a systematic review of the evidence. Adv Parasitol 99: 345-379.

Yapabandara AMGM, Curtis CF and Wickramasinghe MB, Fernando WP (2001) Control of malaria vectors with the insect growth regulator pyriproxyfen in a gem-mining area in Sri Lanka. Acta Trop 80: 265-276.

Zhang X, Mysore K, Flannery E, Michel K, Severson DW, Zhu KY and Duman-Scheel M (2015) Chitosan/interfering RNA nanoparticle mediated gene silencing in disease vector mosquito larvae. J Vis Exp 97: 52523.

Zhang X, Zhang J and Zhu KY (2010) Chitosan/double-stranded RNA nanoparticle-mediated RNA interference to silence chitin synthase genes through larval feeding in the African malaria mosquito (Anopheles gambiae). Insect Mol Biol 19: 683-693. 